\section{SSRI and sympathomimetic interaction}

SIR: Barrett et al (1996) describe two cases of toxicity associated with the combined use of fluoxetine and amphetamine. In both cases, the patients were established on fluoxetine, and had taken only 1 or 2 doses of amphetamine before the acute onset of symptoms associated with psychostimulant overdose or toxicity. Both patients had previously used amphetamine alone, apparently without the development of these symptoms.

One mechanism to account for these cases is a pharmacokinetic interaction between fluoxetine and amphetamine. Amphetamine is metabolised in part by cytochrome P450 2D6 (CYP2D6; Law \& Moody, 1994), and fluoxetine is an extremely potent inhibitor of this enzyme (Crewe et al, 1992). Evidence to support an interaction could be obtained by examining the ratio of amphetamine to its 4-hydroxy metabolite in such cases (it should be increased).

Clinically, one might question the need to use antidepressants in drug-abusing patients, because of concerns over abuse or safety. However, if the use of an SSRI is unavoidable, this interaction could be minimised or avoided by the use of compounds with less potent CYP2D6 inhibitory activity than fluoxetine, such as citalopram or fluvoxamine (Crewe et al, 1992).

Barrett, J., Meehan, O. \& Fahy, T. (1996) SSRI and sympathomimetic interaction (letter). British Journal of Psychiatry, 168 , 253.

Crewe, H. K., Lennard, M. S., Tucker, G. T., et al (1992) The effect of selective serotonin reuptake inhibitors on cytochrome P4502D6 (CYP2D6) activity in human liver microsomes. British Journal of Clinical Pharmacology. 34, 262-265.

LAW, M. Y. L. \& MoODY, D. E. (1994) Urinary excretion of amphetamine and 4-hydroxyamphetamine by Sprague-Dawley and dark Agouti rats. Life Sciences, 54, 1073-1079.

Schering-Plough Research Institute

P. BLUE Kenilworth, NJ 07033

\section{'Psychopaths' in special hospitals}

SIR: The article on Young 'Psychopaths' in special hospitals (Reiss et al, 1996) outlined how an adverse prognostic factor was that of a previous history of sex offending or offending motivated by sexual factors. The study illustrated however that in practice some young 'psychopaths' have a successful treatment outcome. A minority however after discharge committed further serious offences including homicide. Their article is welcome in the context of the pervasive pessimism that is felt about the treatment of 'psychopaths' within general psychiatry and by a sizeable proportion of forensic psychiatrists (Cope, 1993). The subconscious if not conscious rejection of those designated as psychopaths is in my view not only determined by a debate about treatability but also by artificial boundaries on the definition of mental disorder. Pregnancy may not be a disease but it does frequently require clinical management. Psychopaths may not always be mentally ill in the sense of being deluded, hallucinated or in an abnormal mood state, but their psychological processes are abnormal. Indeed they can be distinguished even within a prison setting (Gunn et al, 1991). The co-existence in patients with personality disorder of concurrent episodes of depression, psychosis or brain damage is a familiar clinical finding in both male and female 'psychopaths'.

I personally remain unashamed of retaining the view that, subject to appropriate assessment, some of those with "psychopathic disorder" gain benefit from assessment and treatment in Special Hospitals, although the environment must be therapeutically constructed to maximise personal responsibility of patients while minimising the risk of dangerous behaviour.

COPE, R. (1993) A survey of forensic psychiatrists' views on psychopathic disorder. Journal of Forensic Psychiatry, 4, 215-235.

Gunn, J., Maden, A. \& Swinton, M. (1991) Treatment needs of prisoners with psychiatric disorders. British Medical Journal, 303, 338-341.

Reiss, D., Grubin, D. \& Meux, C. (1996) Young 'psychopaths' in special hospitals: treatment and outcome. British Journal of Psychiatry, 168, 99-104.

\section{Broadmoor Hospital}

H. GORDON

\section{Berkshire RG45 7EG}

Use of vecuronium to prevent suxamethonium-induced myalgia after ECT

SIR: Muscle pains are a well documented adverse effect of ECT and are generally attributed to the use of depolarising muscle relaxants. The reported incidence of postoperative muscle pain following suxamethonium administration varies as widely as $1.5 \%$ to $85 \%$ (Magee \& Robinson, 1987). Although the aetiology of suxamethonium induced myalgia is unclear, several forms of pretreatment successfully reduce the incidence of this adverse effect. The commonest is pretreatment with a small dose of a non-depolarising muscle relaxant such as vecuronium before induction of anaesthesia. Possible complications of this technique include transient diplopia, difficulties with tracheal intubation and prolonged muscle relaxation. An increased dose of suxamethonium may be required to achieve 
adequate muscle relaxation. Other pretreatment techniques reported to be effective include pretreatment muscle stretching exercises (Magee \& Robinson, 1987) and administration of oral aspirin prior to the procedure (McLoughlin et al, 1988).

We report the case of a 19-year-old $(54 \mathrm{~kg})$ woman with major depression who developed severe pain in her upper chest, shoulders and neck for 24 hours after her first and second ECT, in which she was administered thiopentone $250 \mathrm{mg}$ and suxamethonium $35 \mathrm{mg}$ (first treatment) and thiopentone $200 \mathrm{mg}$ and suxamethonium $50 \mathrm{mg}$ (second treatment). The reaction was severe (requiring analgesia with codeine) and distressing. At the third ECT she was pretreated with vecuronium $1 \mathrm{mg}$ three minutes prior to thiopentone $175 \mathrm{mg}$ and suxamethonium $50 \mathrm{mg}$. She recovered quickly from the anaesthesia and suffered no muscle pain or other adverse sequelae. Pretreatment with vecuronium was continued in subsequent treatment sessions and remained effective in preventing myalgia. When pretreatment with vecuronium was omitted on one occasion (with the patient's consent) her myalgia returned.

In this case vecuronium was effective in reducing muscle pain and prevented what could otherwise have been an aversive experience. This technique is mentioned in the APA Task Force Report on ECT (1990), but not in the Royal College of Psychiatrists' guidelines on the administration of ECT (1995). We suggest that pretreatment with vecuronium should be considered for patients who complain of muscle pains following ECT. This case also highlights the benefits of continuity of care, whereby the same doctor applying the ECT also monitored the patient's progress after and between treatments, enabling appropriate feedback to be given to the anaesthetist.

American Psychiatric Association (1990) The Practice of Electroconvulsive Therapy: Recommendations for Treatment, Training and Privileging. Washington, DC: APA.

Magee, D. A. \& Robinson, R. J. S. (1987) Effect of stretch exercises on suxamethonium induced fasciculations and myalgia. British Journal of Anaesthesia, 59, 596-601.

Mcloughlin, C., Nesbitt, G. A. \& Howe, J. P. (1988) Suxamethonium induced myalgia and the effect of pre-operative administration of oral aspirin. Anaesthesia, 43, 565-567.

Royal College of Psychiatrists (1995) The ECT Handbook. The Second Report of the Royal College of Psychiatrists Special Committee on ECT. London: Royal College of Psychiatrists.

\section{P. M. HERRIOT \\ T. CowaIn \\ D. MCLEOD}

Flinders Medical Centre

Bedford Park 5042

Australia

\section{HIV and mental illness}

SIR: The review on HIV infection and mental illness (Stefan \& Catalan, 1995) raises several important issues. In order to plan appropriate intervention strategies and study geographical variations it is important to describe the prevalence of infection among subgroups of psychiatrically ill.

We analysed data of 2139 psychiatric in-patients who were tested for HIV infection during the period January 1992 to December 1995 at the National Institute of Mental Health \& Neurosciences, Bangalore, India. They accounted for $18 \%$ of the in-patient admissions during this period. In 1200 patients testing was done because of an identifiable risk factor, 150 patients were tested because of suspicion of an AIDS-related condition while in 789 patients no reason was documented.

Among those with risk behaviour, in $67 \%$ the risk was in the form of multiple heterosexual partners, $15 \%$ used i.v. drugs, $7 \%$ had multiple homosexual partners and $11 \%$ had a history of sexual abuse. Seropositivity was detected in 35 patients i.e. $3.4 \%$ of the risk group. All the seropositives had a history of multiple heterosexual partners and in three there was a history of comorbid i.v. drug use. Their psychiatric diagnoses were as follows - alcohol dependence $(29 \%)$, i.v. drug use $(8.5 \%)$, personality disorders $(34 \%)$, bipolar affective disorder (11.5\%), schizophrenia $(11.5 \%)$ and dementia (7.5\%). Comorbid alcohol dependence was present in $85 \%$ of the seropositives. None of the patients had been aware of their HIV status prior to admission.

An important finding in our study was the high prevalence of comorbid alcohol dependence in our seropositive group and the preponderance of personality disorders. Our data also indicates the need for discretional testing with a detailed assessment of risk behaviour rather than routine testing, especially in areas, including India, where seroprevalence is low.

Stefan, M. D. \& Catalan, J. (1995) Psychiatric patients and HIV infection - a new population at risk? British Journal of Psychiatry, 167, 721-727.

P. S. Chandra

V. RAVI

S. Puttaram

A. Desai

National Institute of

Mental Health \& Neurosciences

Bangalore 560029

India 